\title{
Optimization of submerged vane parameters
}

\author{
H SHARMA*, B JAIN and Z AHMAD \\ Department of Civil Engineering, Indian Institute of Technology Roorkee, Roorkee, Uttarakhand 247667, India \\ e-mail: smile4anshu@gmail.com; bhupeshjkain@gmail.com; zulfifce@gmail.com
}

MS received 21 April 2015; revised 21 July 2015; accepted 26 September 2015

\begin{abstract}
Submerged vanes are airfoils which are in general placed at certain angle with respect to the flow direction in a channel to induce artificial circulations downstream. By virtue of these artificially generated circulations, submerged vanes were utilized to protect banks of rivers against erosion, to control shifting of rivers, to avoid blocking of lateral intake with sediment deposition, etc. Odgaard and his associates have experimentally obtained the optimum vane sizes and recommended that it can be used for vane design. This paper is an attempt to review and validate the findings of Odgaard and his associates by utilizing computational fluid dynamics and experiments as a tool in which the vane generated vorticity in the downstream was maximized in order to obtain optimum vane parameters for single and multiple vane arrays.
\end{abstract}

Keywords. Submerged vanes; vorticity; optimization; circulations; computational fluid dynamics.

\section{Introduction}

Submerged vane is basically an aerofoil structure, which generates the excess turbulence in form of helical flow structure in the flow due to pressure difference between approaching flow side and downstream side of vane [1-4]. These vanes are in general placed at certain angle with respect to the flow directions which is usually $10^{\circ}-40^{\circ}$. Submerged vanes utilize vorticity to minimize the drag and produce flow redistribution in the flow such that longitudinal flow is compelled to get diverted towards the transverse direction [4]. By virtue of these generated circulations submerged vanes were used as a tool to protect river bank erosion [2, 5], river bed erosion [1], river bend [6, 7], shoaling of intake $[8,9]$, etc. Odgaard and his associates provided recommendations regarding the vane parameters which included vane angle of attack, height of vane and length of vane in case of single vane. In case of multiple vanes, they optimized the lateral and longitudinal spacing of vanes, which can be seen in table 1. In present study, an attempt is made to establish validity of recommendations provided by Odgaard and his associates regarding vane parameters by using Computational Fluid Dynamics $(k-\omega$ turbulence model was used to model the flow) as a tool in which vorticity in the downstream of vane was maximized in order to optimize the vane parameters. Also in the present study, flow downstream of single and multiple vane array was studied (figure 1).

\footnotetext{
*For correspondence
}

\section{Development of model}

Geometry to be created in ANSYS-CFX is a rectangular channel of $1.0 \mathrm{~m}$ width, $0.1241 \mathrm{~m}$ depth and $19 \mathrm{~m}$ length. Study was conducted using three vane sizes. The size of vanes used were $0.02 \mathrm{~m}$ high $\times 0.05 \mathrm{~m}$ long, $0.04 \mathrm{~m}$ high $\times 0.10 \mathrm{~m}$ long and $0.06 \mathrm{~m}$ high $\times 0.12 \mathrm{~m}$ long. Although vane size of length $=0.12 \mathrm{~m}$; height $=0.06 \mathrm{~cm}$; and thickness $=0.002 \mathrm{~m}$ was utilized in order to study the flow pattern and to optimize vane parameters by using the magnitude of vorticity as a criterion of optimization, which was shown by various investigators $[1-4$, etc.]. The submerged vanes were placed at mid-width of the channel i.e., $0.5 \mathrm{~m}$ from either of the banks and were placed $6.53 \mathrm{~m}$ downstream from the inlet of the flume, for single vane study. In case of multiple vane arrays, the vanes were placed at the distance of $3.5 \mathrm{~m}$ from the inlet section and in a row of seven vanes each being separated by a lateral distance of $0.125 \mathrm{~m}$. First vane of row was having a lateral distance of $0.08 \mathrm{~m}$ from the left wall of flume. A sum total of four vane rows were utilized in order to measure the flow pattern around submerged vane. After creating the geometry of the vane containing vane, the geometry was meshed by utilizing appropriate meshing in order to visualize the flow structure around the vane. After creation of the geometry, 3D blocking was initialized. A suitable blocking was created around the vane rows so as to completely cover the vane domain. All the rows were being covered up by blocks created by edge splitting and each of the vertices created was associated with a point. After being done the point-vertices association, blocks around the vanes were assigned as the SOLID blocks. A pre-mesh was created. A 
Table 1. Recommended dimensions of submerged vanes.

\begin{tabular}{|c|c|c|c|c|c|c|}
\hline Investigators & $\begin{array}{l}\text { Skew } \\
\text { angle }\end{array}$ & $\begin{array}{l}\text { Length of vane-height } \\
\text { of vane ratio }\end{array}$ & $\begin{array}{l}\text { Height of vane-depth } \\
\text { of flow ratio }\end{array}$ & $\begin{array}{l}\text { Length of vane-depth } \\
\text { of flow ratio }\end{array}$ & $\begin{array}{c}\text { No. of vanes } \\
\text { per array }\end{array}$ & $\begin{array}{l}\text { Vane array } \\
\text { spacing }\end{array}$ \\
\hline $\begin{array}{l}\text { Odgaard and } \\
\text { Wang [3] }\end{array}$ & $\begin{array}{r}15^{\circ}- \\
30^{\circ}\end{array}$ & $0.1-0.5$ & $0.2-0.4$ & $0.3-0.5$ & 3 & $\begin{array}{l}\leq 30 \text { times } \\
\text { vane height }\end{array}$ \\
\hline $\begin{array}{l}\text { Wang and } \\
\text { Odgaard [4] }\end{array}$ & $\begin{array}{r}15^{\circ}- \\
30^{\circ}\end{array}$ & $0.1-0.5$ & $0.2-0.5$ & $0.3-0.5$ & N/A & 2-3 \\
\hline $\begin{array}{l}\text { Marelius and } \\
\text { Sinha [10] }\end{array}$ & $40^{\circ}$ & N/A & N/A & N/A & N/A & N/A \\
\hline Tan et al [12] & $30^{\circ}$ & N/A & 0.2 & $\begin{array}{c}\leq 2-3 \text { times dune } \\
\text { length }\end{array}$ & N/A & N/A \\
\hline
\end{tabular}

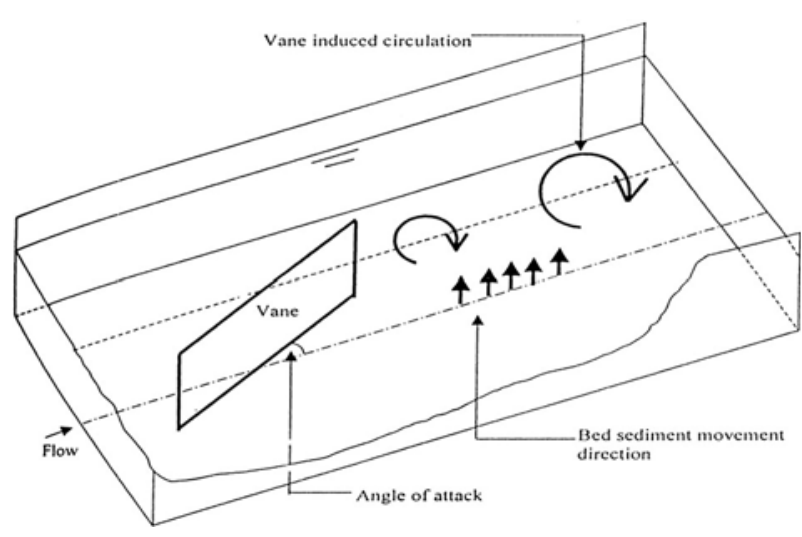

Figure 1. Submerged vane induced transverse circulations.

non-uniform mesh was created by clicking right mouse button around pre-mesh option. After creation of non-uniform mesh in blocks around submerged vanes, mesh quality was checked which came out as 0.83 . In order to have a good mesh, mesh quality should be greater than 0.3 (ICEM CFD Manual, 2011). After the complete meshing of the geometry, all the sides were classified according to their boundary conditions. In the inlet boundary conditions, a uniform flow boundary condition was assumed and an average velocity of $0.41 \mathrm{~m} / \mathrm{s}$ was given as initial velocity from the inlet boundary. At the exit plane, all the variables were obtained by assuming zero streamwise diffusion or motion. Solid boundaries were entitled to "WALL" boundary conditions, which acclaims that there must be no cross flow through it or normal gradient to the wall is always zero - this condition is known to be "no-slip" condition. In boundary conditions assigned to solid boundaries, all were classified as smooth boundaries. Water surface was modeled by assuming it to be a hard sloping lid across which there is no flow possible. In order to compute the velocity, it was assumed that water is flowing with the same inlet velocity along the water surface. Also in order to measure the water surface elevations and to check the uniformity of flow, water surface elevations were taken at three different sections. It was observed that flow was completely uniform and flow only varied at the maximum of $0.2 \mathrm{~mm}$ within the three sections, hence practically flow can be termed as a uniform flow. Hence, a "SYMMETRY" boundary condition was applied to it.

\section{Experimental set-up}

The experiments were performed at the Hydraulics Laboratory of Civil Engineering Department, Indian Institute of Technology Roorkee. The experiments were performed in a recirculating concrete flume of width $1.0 \mathrm{~m}$, depth $0.30 \mathrm{~m}$ and length $19 \mathrm{~m}$. The bed slope of the flume was 0.000632 . The water was supplied to the flume through an overhead tank, in which the level of water was kept constant, to have a constant discharge for a particular opening of the valve-fitted in the delivery pipe of the tank. An orifice meter was also fitted in the delivery pipe for discharge measurement. Flow from the flume was taken into a sump through a channel fitted with sharp-crested weir used for the discharge measurement. Water was again lifted using a pump to the overhead tank. Two rows of grid walls, flow straighteners and wooden wave suppressor were provided upstream of the channel to stabilize the flow. A tail gate was provided at the end of the flume to maintain a uniform flow. The railing of the flume was made parallel to the bed prior to conductance of the experiment (figures 2 and 3).

Four rows of submerged vanes were attached to the bed so as to perform experiments for studying flow pattern around submerged vanes. Vanes used in experiments were $0.06 \mathrm{~m} \times 0.12 \mathrm{~m}$ whose lateral spacing was $0.125 \mathrm{~m}$ respectively and each row was separated by a longitudinal distance of $1 \mathrm{~m}$. In order to measure the velocity, mini Acoustic Doppler Velocimeter (ADV) was used over the sections $x=3 \mathrm{H}, 8 \mathrm{H}$ and $20 \mathrm{H}$ from the last vane row, where $\mathrm{H}$ is the height of the vane. Velocity was measured initially for four vane rows and after measuring the flow pattern around submerged vane, a vane row was removed and process was repeated and finally the final flow pattern was measured for plane shear flow condition (figure 4). 


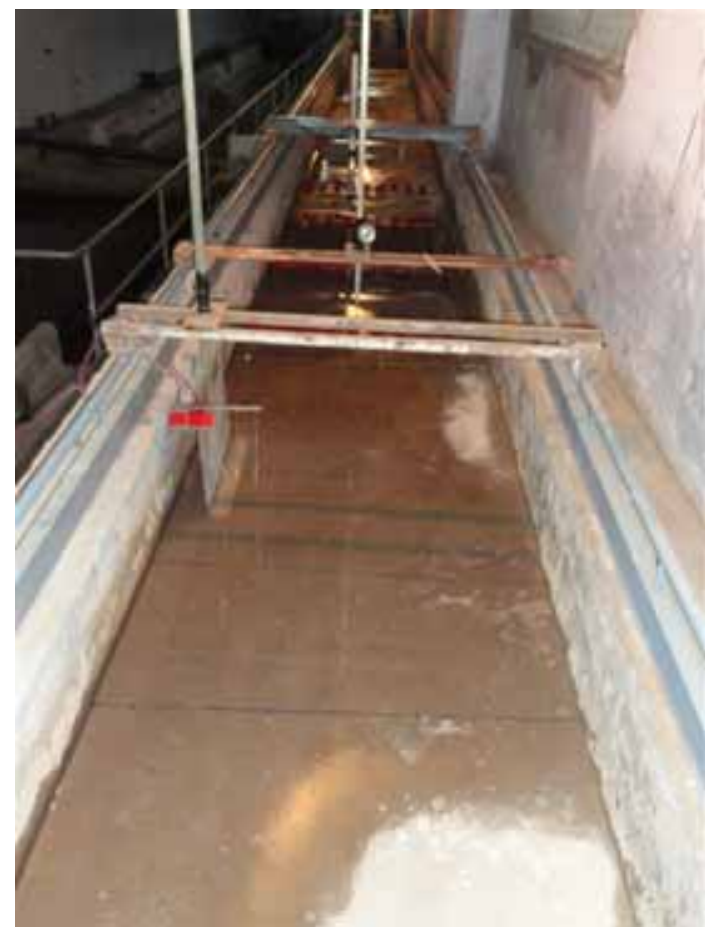

Figure 2. Photograph showing the flume with arrays of submerged vanes.

\section{Validation of model}

CFD is an easy tool to compute and demonstrate how flow is behaving in complex situation without performing experiments in reality. Since, many a times the CFD tool generates and captures the flow pattern in an efficient way but is not able to regenerate the magnitude of flow field in an accurate manner. Thus, it is essential to validate the developed model so as to investigate the flow pattern and various flow quantities which are hard to measure experimentally. In order to validate the present model, study conducted by Wang and Odgaard [4] was considered. Wang and Odgaard [4] conducted experiments for single vane and multiple vane arrays. Bed of the channel was fully covered with sand of size $4 \mathrm{~mm}$. Vane was cut from a metal sheet of thickness $0.75 \mathrm{~mm}$ and length of vane was $15.2 \mathrm{~cm}$ while the height was kept as $7.6 \mathrm{~cm}$. Depth of flow maintained by Wang and Odgaard [4] during their experimentation was $15.2 \mathrm{~cm}$ and average velocity of flow was $0.24 \mathrm{~m} / \mathrm{s}$. In the CFD model, an arbitrary length of $10 \mathrm{~m}$ was assigned as the length of the model, since Wang and Odgaard [4] did not mention the length of channel.

After creating the model with dimensions described by Wang and Odgaard [4] in their study, suitable boundary conditions were applied to each boundary of the model. At the inlet of channel a uniform flow of velocity $0.24 \mathrm{~m} / \mathrm{s}$ was introduced and flow velocity was investigated at $\mathrm{x}=3 \mathrm{H}$, $8 \mathrm{H}$ and $20 \mathrm{H}$, where $\mathrm{H}$ is the vane height, which were the transects at which Wang and Odgaard [4] experimentally measured the value across channel cross-section. Results of simulation were compared with experimental results obtained by Wang and Odgaard [4] and it can be seen in figure 5 . It can be clearly seen from figure $5 \mathrm{a}$ and $\mathrm{b}$ that velocities simulated from CFD using standard $k-\omega$ model were very much in accordance with what it was measured by Wang and Odgaard [4]. Thus, model can be used to study the turbulence characteristics around submerged vanes and to predict various parameters downstream of the submerged vanes. After the model validation, grid-dependency test was performed for the model. In the grid-dependency test, two meshes, in which one finer mesh than the present mesh and one coarser mesh than the present mesh were used to compute transverse velocity. It was observed that no formidable differences were observed in the transverse velocity. Thus, one can observe that results obtained were completely grid-independent.

\section{Optimization of vane parameters}

\subsection{Vane angle}

Angle of attack of submerged vane always remained as a topic of ambiguity due to various investigations done on it by various investigators. Odgaard and associates $[1-3,5$, etc.] have advocated the angle of attack of vane to be in between $15^{\circ}$ and $30^{\circ}$. Wang and Odgaard [4] suggested angle of attack should be $30^{\circ}$ in order to generate optimum strength of secondary currents. Marelius and Sinha [10] by using the moment of momentum principle showed that in order to generate optimum strength of vortical currents from the submerged vane, the angle of attack must be $40^{\circ}$. While, Johnson et al [11] during their experimentations with rock vanes as controller of vertical wall abutment scour, observed that vane angle of $30^{\circ}$ serves as optimum angle which can reduce the scouring in an effective manner. Voisin and Townsend [7] observed that by keeping an angle of attack of $2^{\circ}$ with respect to the flow, optimum secondary currents may be generated to counteract bend generated currents. Tan et al [12] also suggested angle of attack as $30^{\circ}$ for maximum diversion of sediment. Bhuyian et al [13] also observed that angle of attack of $30^{\circ}$ generates the maximum secondary current. Gupta et al [14] also proposed angle of submerged vane to be $40^{\circ}$ with collar so that scour around pier can be reduced. In the present study, a single vane of size $6 \mathrm{~cm}$ high and $12 \mathrm{~cm}$ long was placed $1 \mathrm{~m}$ downstream of the inlet of model. Depth of flow was kept as $12.4 \mathrm{~cm}$. After defining each boundary, angle of attack of vane was changed and four angles of attack were chosen which were $15^{\circ}, 30^{\circ}, 45^{\circ}$ and $60^{\circ}$. At the downstream at a distance of two times of vane height (i.e., $12 \mathrm{~cm}$ downstream) from the center of the vane, vorticity in $x$ direction was measured as can be seen in figure 6 . It was observed that for $30^{\circ}$ angle of attack, the maximum value of vorticity was obtained and it was in accordance with the various investigations done 


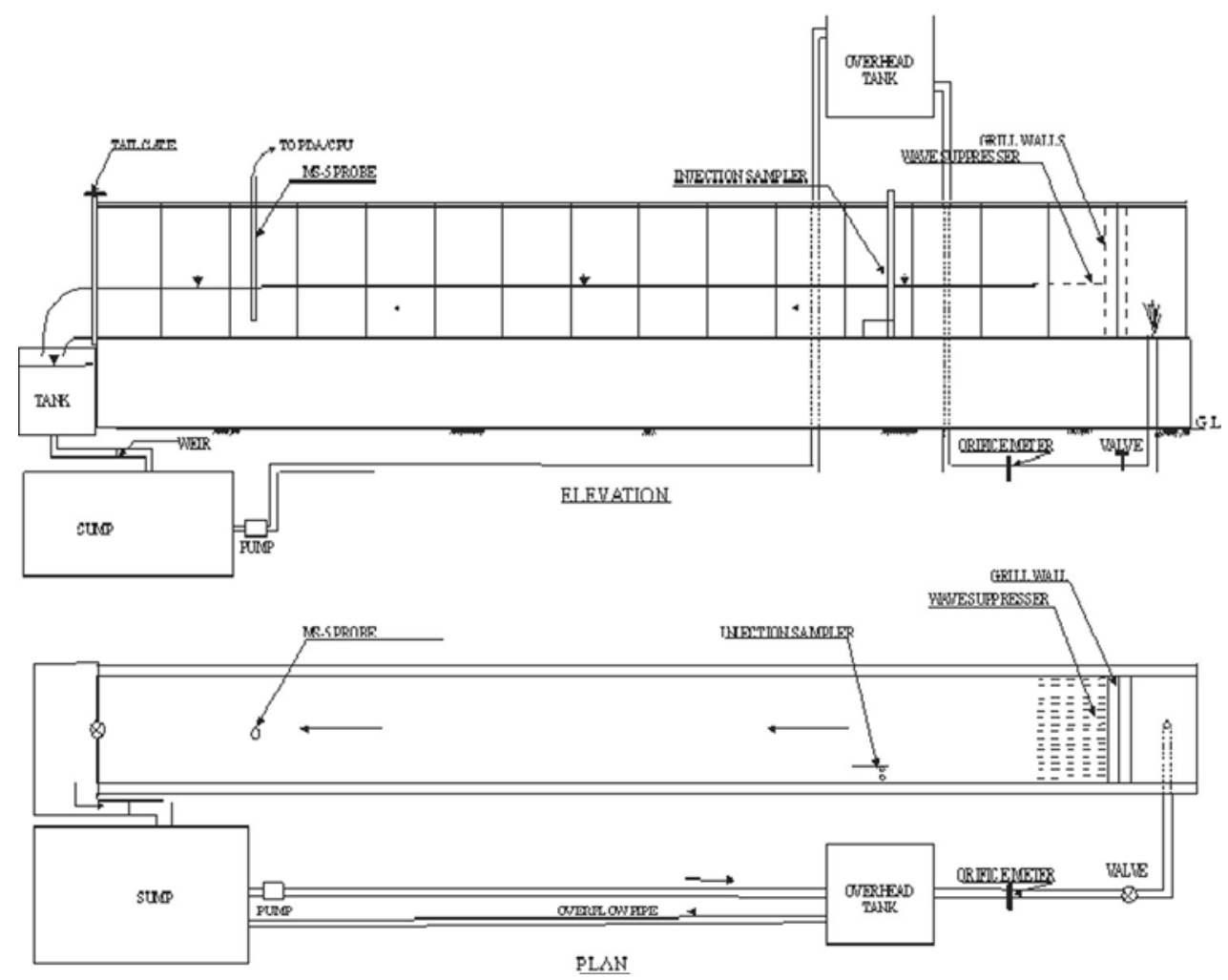

Figure 3. Layout of experimental set-up.

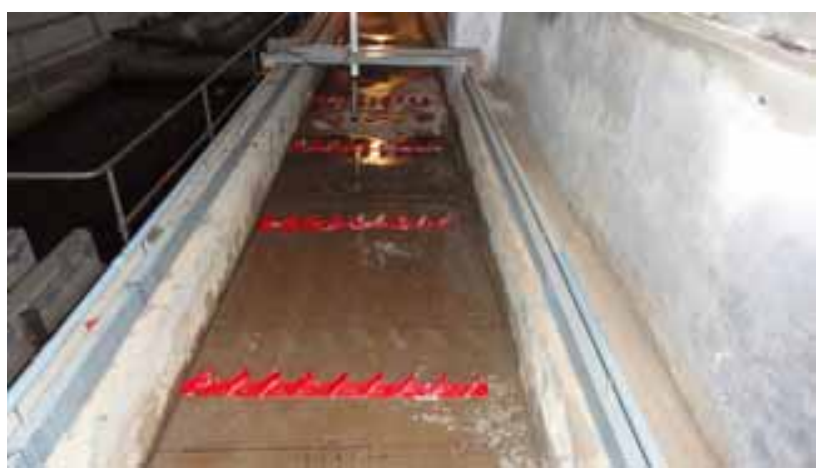

Figure 4. Arrays of installed vanes.

previously. Thus, it can be suggested that for an angle of attack of $30^{\circ}$, optimal strength of vorticity is generated and can be utilized for various purposes having its effect in far reaches in downstream.

\subsection{Height of vane}

Vane height is again an important parameter which is associated with the generation of vortices. Odgaard and Kennedy [5], Odgaard and Spoljaric [1] and Odgaard and Mosconi [2], all suggested to keep the height of the vane $0.2-0.5$ times the depth of flow. Odgaard and Wang [3] also suggested height of vane to be $0.2-0.4$ times the flow depth in order to generate optimum secondary currents. Voisin and Townsend [7] proposed that for vane height 0.35 times the depth of flow, vane generates sufficiently strong currents to preserve the bend walls. Tan et al [12] observed that when vane height was within $1 / 8$ th-1/3rd the depth of flow, it deviates the maximum sediment towards the bank. Flokstra [15] suggested a vane height $\leq 0.4$ times the depth of flow. Ouyang [16] suggested that when vane height is $0.58-0.70$ times the water flow depth, it generates efficient vortical flow. In the present study, submerged vanes with heights varying from 0.2 times to 0.6 times the flow depth were considered. It was observed that for vane height equal to 0.4 times the depth of flow, maximum vorticity was generated, which was in accordance with the previous studies conducted and was very much near to the optimum height proposed by Voisin and Townsend [7]. Variation of vorticity with vane height can be seen in figure 7 .

\subsection{Length of vane}

Length of vane is associated with the amount of drag and lift produced around the hydro-foil. More is the length, more will be the contact-drag which in turn will give rise to a higher lift. For a constant free stream velocity and density of fluid, that is the condition which prevails here, in accordance with the Kutta-Juokowski theorem, lift 

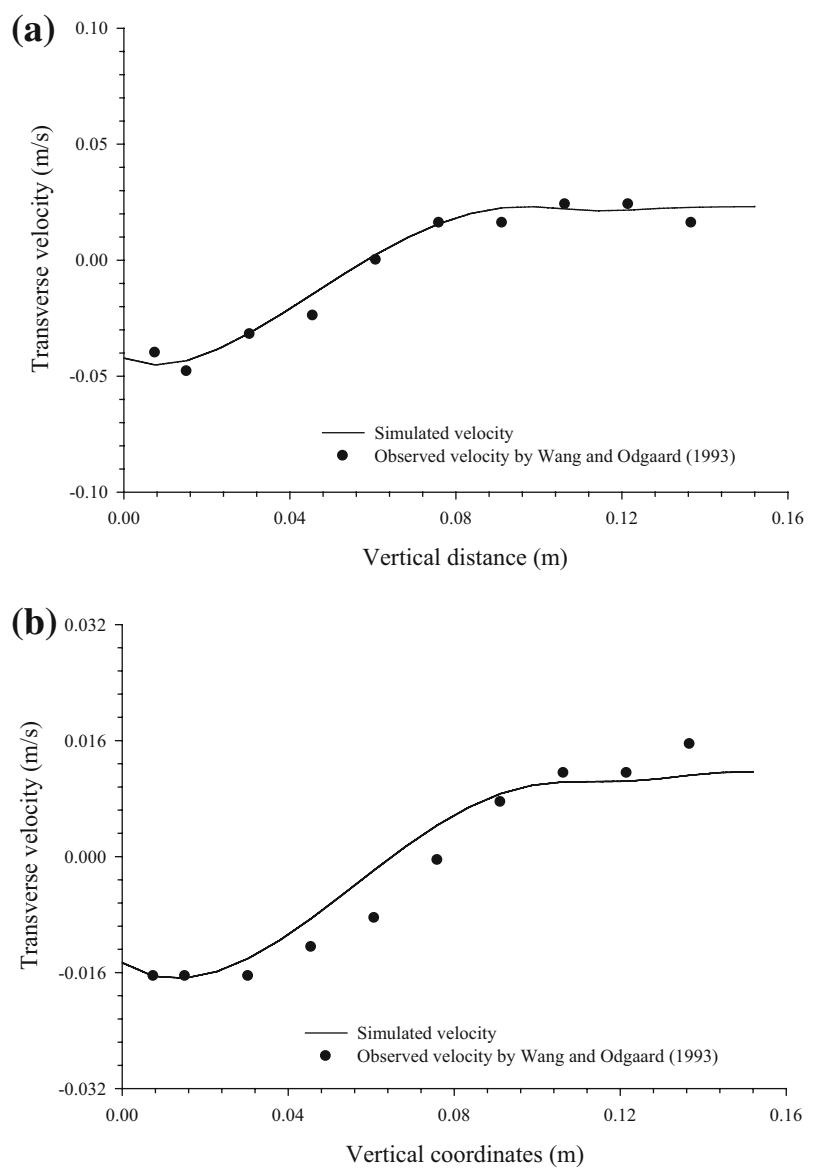

Figure 5. Validation of single vane model for (a) $\mathrm{x}=8 \mathrm{H}$ and (b) $\mathrm{x}=20 \mathrm{H}$.

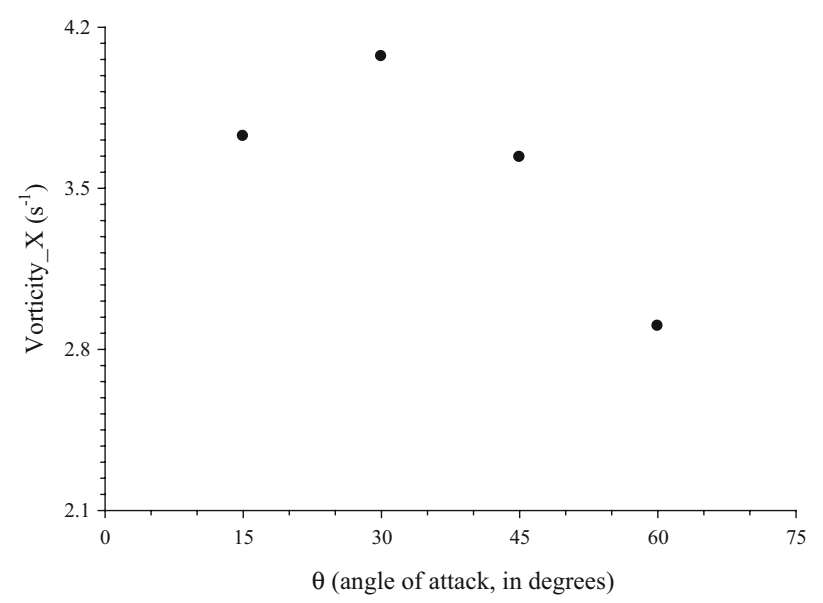

Figure 6. Variation of vorticity with angle of attack.

generated is proportional to the strength of circulation generated by airfoil/hydrofoil and vice-versa [17]. Odgaard and Spoljaric [1] observed that keeping length of vane in between 2.5 and 3 times, vane height will generate optimum amount of circulation to counteract process of bed

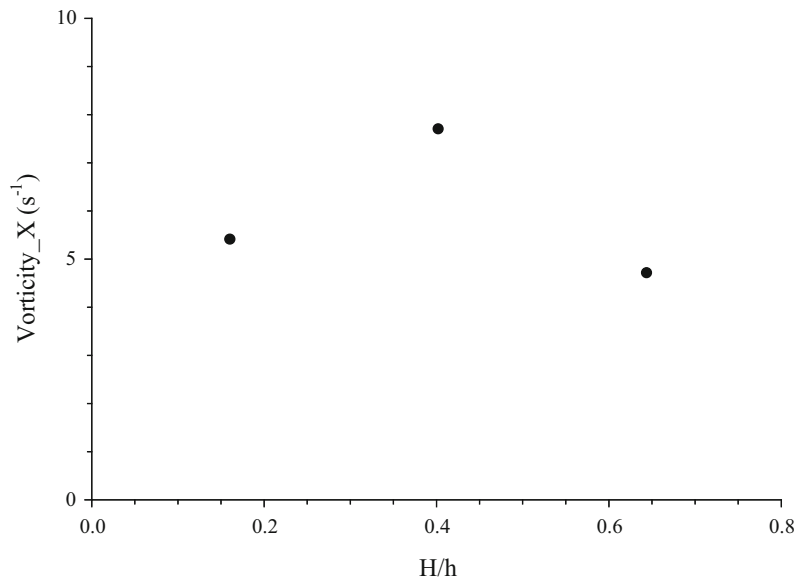

Figure 7. Variation of vorticity with vane height.

erosion. Voisin and Townsend [7] proposed that optimum length for vane should be 0.33 times the width of channel. Flokstra [15] in a study observed that model works well if length of submerged vane varies 4-8 times vane height. Ouyang et al [18] in their study observed that by changing the height or length of the submerged vane, no effective change in bed profile was observed. Ouyang [16] observed that increasing length will decrease the efficiency of vane and hence proposed a length of vane to be 0.5 times the depth of flow. It can be observed that very little study has been conducted on the length of submerged vane. In the present study three vane lengths of submerged vanes were chosen which were $\mathrm{H}, 2 \mathrm{H}$ and $5 \mathrm{H}$.

It can be seen from figure 8 that as the length of vane was increasing, more area was available for fluid to have more drag around the vane. More drag around vane will give rise to more lift as stronger vortices will be generated from the vortex bounding the vane and hence an increase in vorticity was observed which was in accordance with Kutta-Juokowski theorem [17].

\section{Flow pattern around and downstream of vane}

From figures 9 and 10, it can be seen that the flow downstream of vane is a highly turbulent flow. A large spiraling motion was seen downstream of submerged vane. Similar observation was made by Odgaard and Kennedy [5], Odgaard and Spoljaric [1], Odgaard and Wang [3], Wang and Odgaard [4], Marelius and Sinha [4], Sinha and Marelius [19], Voisin and Townsend [7], Tan et al. [12], etc. It can be seen from figure 10 that leading edge was responsible for the generation of vortical structure by accelerating the flow around it, similar observation was observed by Odgaard and Wang [3] and Wang and Odgaard [4]. They suggested that due to the leading edge, a high velocity field is formed around it and due to the accelerating flow a region of negative pressure gradient is 


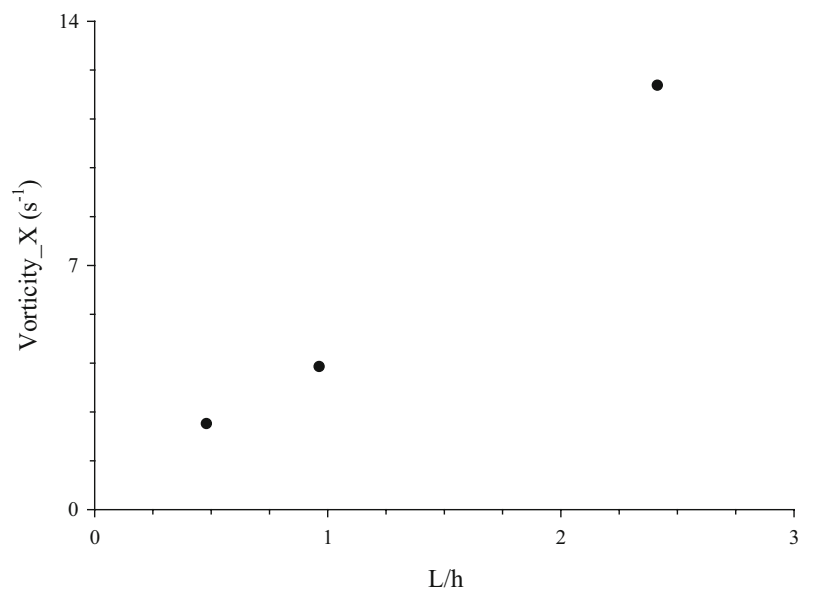

Figure 8. Variation of vorticity with vane length.

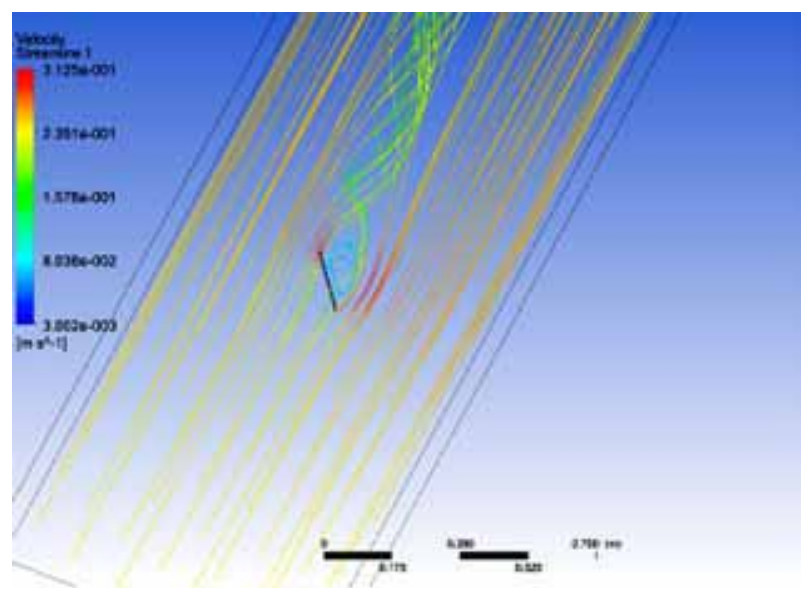

Figure 9. Velocity variation downstream of vane.

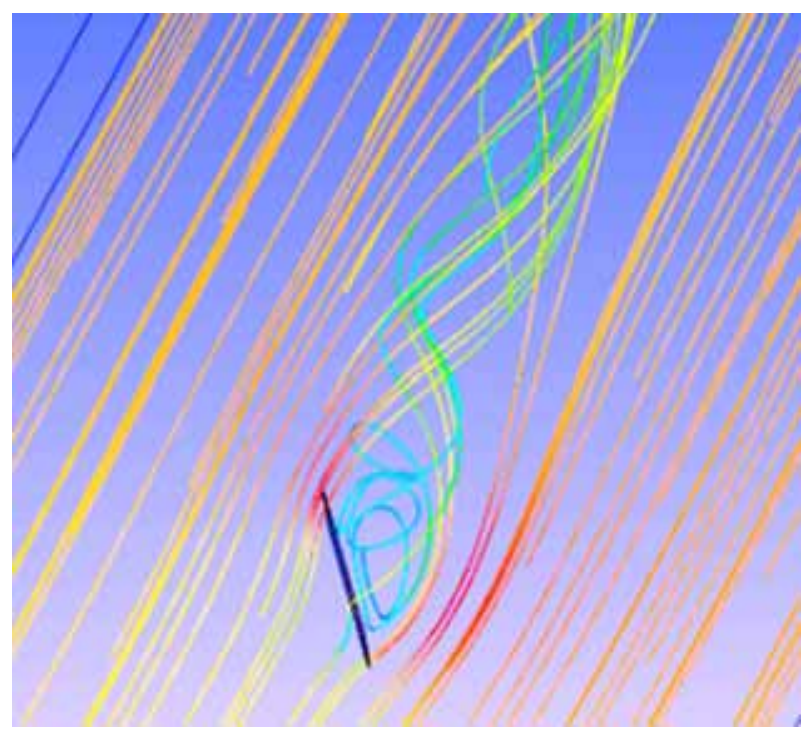

Figure 10. Planimetric view of flow pattern downstream of a submerged vane. generated resulting in separation of flow from vane tip and hence, they termed these vortices to be tip vorticies. In the downstream of vane a pair of clockwise and anti-clockwise vortices can be seen, which is in accordance with the observations of Marelius and Sinha [10].

Marelius and Sinha [10] suggested that due to the proximity of stagnation line to leading edge than to trailing edge, trailing edge is available for large pressure field. Thus, vortex generating around leading edge breaks down due to the less pressure gradient field and forms a pair of clockwise and anti-clockwise vortices. Tan et al [12] described that flow over the vane just acts like flow over any weir; it plunges over the vane, speeds up the bed velocity and re-generates the vortical cells. A similar observation was seen where a streamline was observed to plunge, again lifts up getting accelerated and then joins the vortex sheet generated from separation of flow from the leading edge.

It can be seen in figure 11 that vorticity rises to maximum when trailing edge is reached which is near $1.12 \mathrm{~m}$ from the inlet, which signifies the fact that trailing edge also induces the vorticity in the flow which was in accordance with the observation of Odgaard and Wang [3] and Wang and Odgaard [4]. It was observed that as the flow recedes from the trailing edge, the viscosity of flow comes into the action and vorticity in the flow dissipates in an exponential manner after achieving a peak value. Marelius and Sinha [10] by using moment of momentum or angular momentum as an indicator of vorticity observed similar pattern. Turbulent kinetic energy is basically a measure of the amount of turbulence generated in the flow. Since the submerged vane is acting as an obstruction to the flow, it will generate large amount of turbulent kinetic energy in the form downstream vortical flow. It was observed that at the upstream of the submerged vane, turbulence was zero and as the leading edge was approached by the flow a sudden leap in the kinetic energy was observed (figure 12). This clearly indicates that flow is rather affected by leading edge

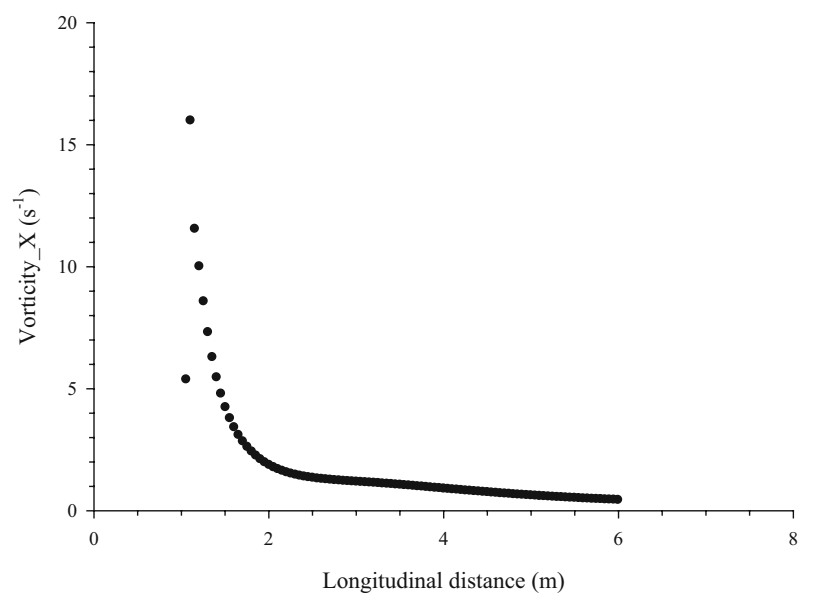

Figure 11. Variation of vorticity downstream of submerged vane. 


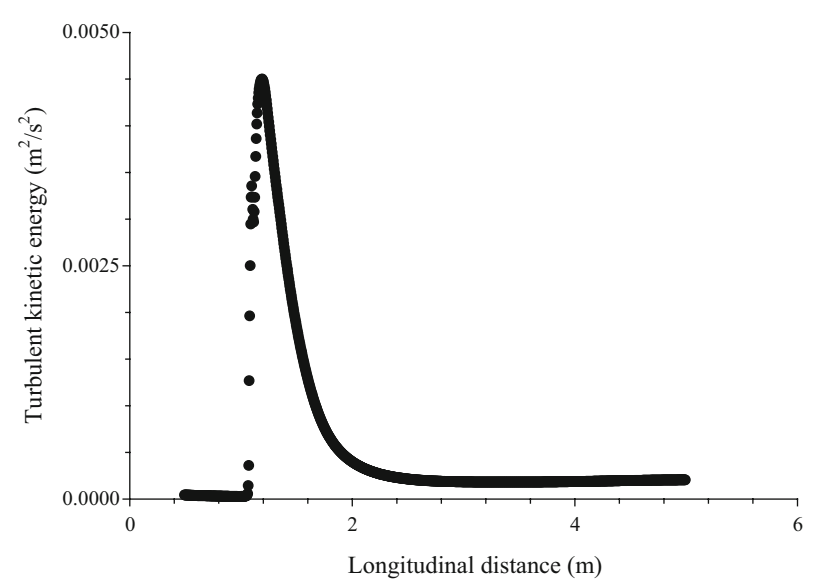

Figure 12. Variation of turbulent kinetic energy after insertion of submerged vane.

than the trailing edge in the formation of vortices. Similar observation was made by Marelius and Sinha [10] in their experimental study. As the flow recedes away from trailing edge there is an exponential drop in the turbulent kinetic energy. The reason behind this drop is that the vortices separate from the vane, which is acting as source of turbulence generation is now far away from the vortices. This gives chance to viscous forces to act over the vortices and dampen them to make flow as smooth and undisturbed as possible.

\section{Optimization of vane parameters in multiple vane arrays}

\subsection{Validation of model}

\subsubsection{Validation of model with transverse} velocity: In order to validate the model for the flow pattern similarity with those discussed in various earlier literature, analysis was performed by comparing the observations from experiments with the predicted velocity profile. A channel was created with dimensions $19 \mathrm{~m}$ long, $1 \mathrm{~m}$ wide and $0.124 \mathrm{~m}$ deep. Twenty-eight numbers of submerged vanes were created with dimensions as $0.12 \mathrm{~m}$ long, $0.06 \mathrm{~m}$ high and $0.002 \mathrm{~m}$ thick and were aligned with the direction of flow with angle of attack of $30^{\circ}$. Each vane array was having lateral spacing of $0.125 \mathrm{~m}$ between two vanes and each vane array constituted of four vanes with seven rows separated by $1 \mathrm{~m}$ in longitudinal direction. Not only flow pattern was measured and validated for four vane rows but also flow was measured for three, two and one vane rows and was validated for model developed for respective vane rows. In order to validate the model, a plot was drawn in which transverse velocity predicted from model was compared with the observations of present experiments. It can be seen from figures 13 and 14 that simulated velocity profile is comparable to the observed
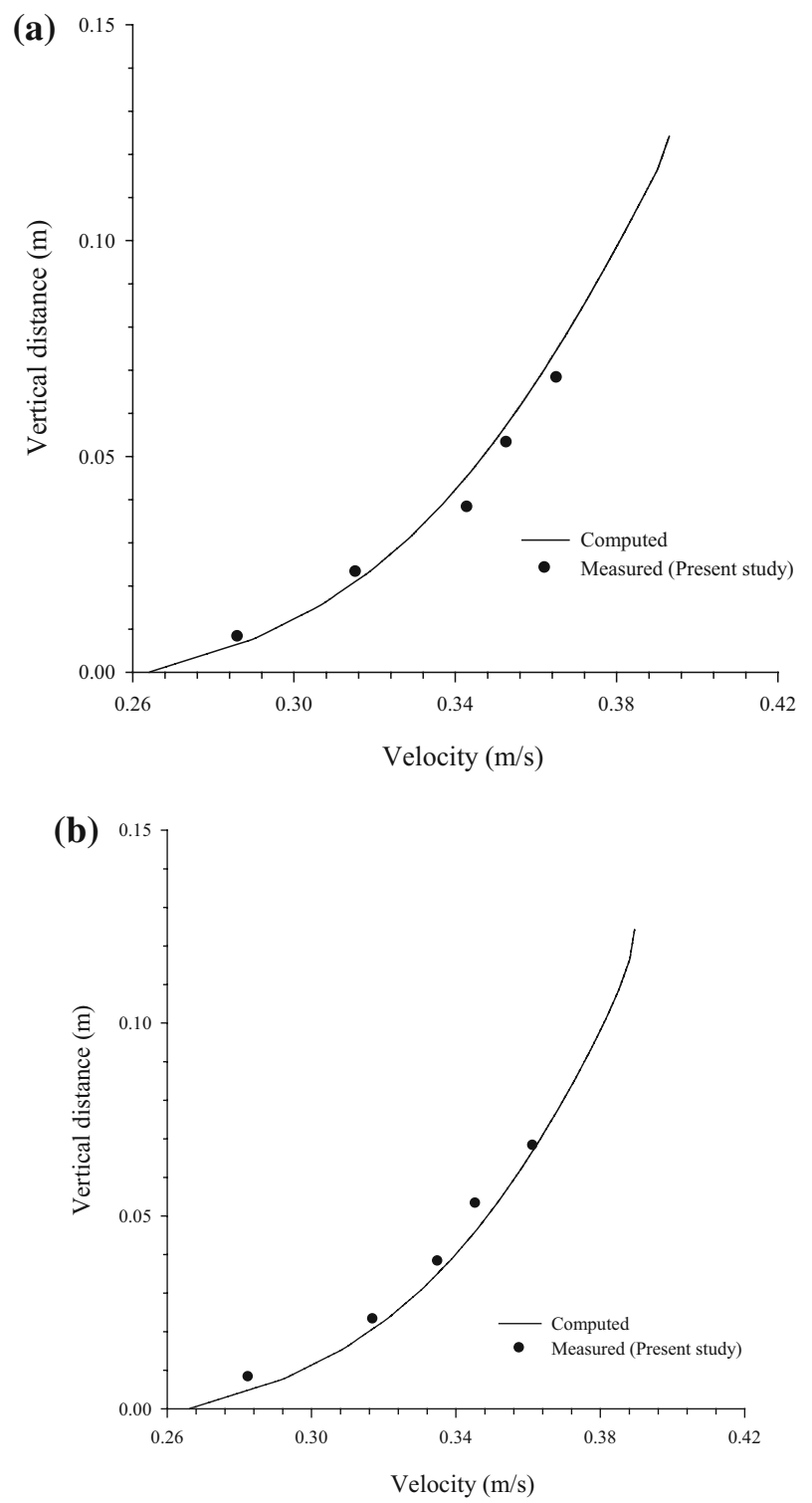

Figure 13. Validation of continuity of model for (a) $x=3 \mathrm{H}$ and (b) $\mathrm{x}=20 \mathrm{H}$.

data. The probable reason behind this anomaly may be due to the fact that numerical model does not account for the vortices generated by separation from leading edge and only models the trailing edge generated vortices which enhances the lateral component of velocity.

7.1.2 Transverse spacing of vane array: Transverse spacing of vanes in an array is an essential component in generating a coherent structure which enhances the chance of degradation of bed and bank reduced, effectively. According to Odgaard and Wang [3], each submerged vane acts as an individual vortex generator and generates a sheet of vortices in downstream. According to Odgaard and Wang [3], if the vanes are placed very near to each other, 

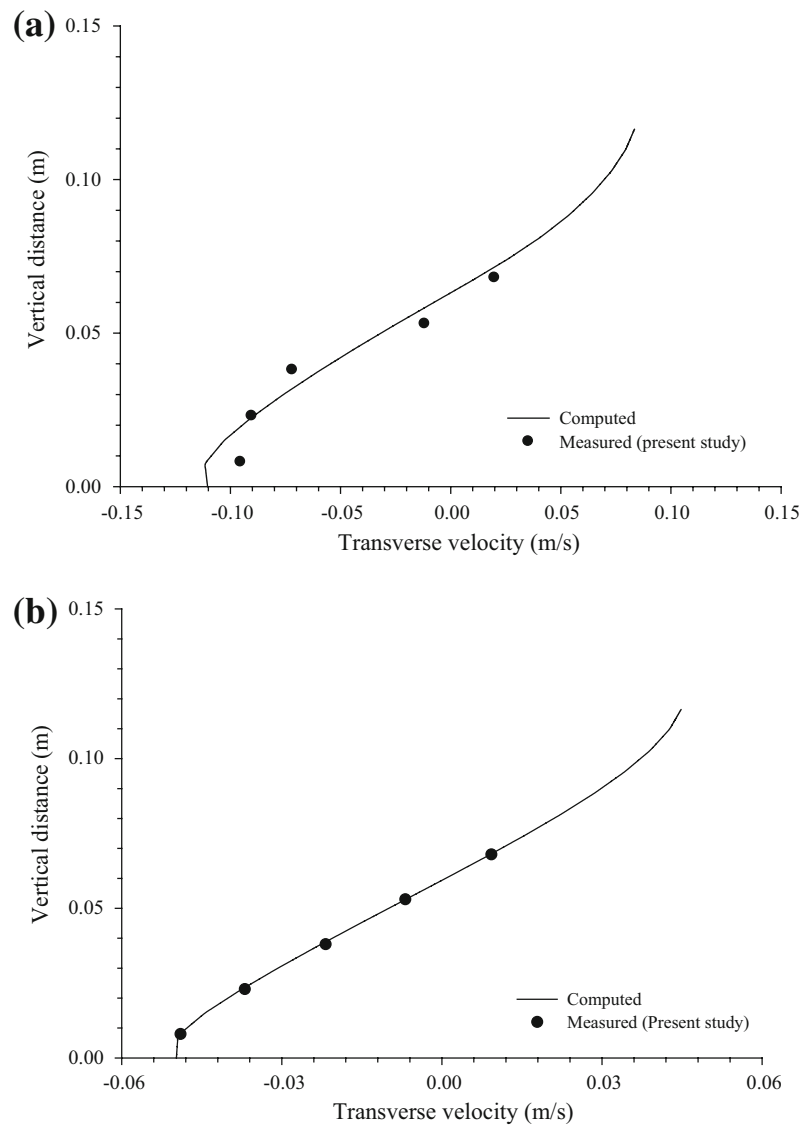

Figure 14. Validation of model from observations of present experimentations.

each vortex will interact with each other and would reduce the effective circulation and effectiveness of vanes will be reduced. If the vanes are spaced very far, each vane will generate individual vortices which will be dissipated very easily and again vanes will be ineffective, which is what Odgaard and Wang [3] observed. Thus, they optimized the spacing between vanes as 2-3 times vane height in which vanes will interact effectively and will generate a coherent structure downstream of the array, which in turn will help the vanes to work effectively. Wang and Odgaard [4] supported the observation of Odgaard and Wang [3] and justified that in the presence of down-wash component over vane, the effectiveness of vane will be less if they are very close and vanes will not be able to interact to generate a coherent structure, if vanes are placed far in transverse direction. Hence, Wang and Odgaard [4] also suggested that 2-3 times $\mathrm{H}$ is an optimum spacing in order vane generates an optimized circulation in the downstream. Voisin and Townsend [7] proposed that optimum transverse spacing between two vanes be 0.24 times channel width. Flokstra [15] agreed with the observation of Odgaard and Wang [3] that the presence of vane in the neighborhood interferes with the circulation generation and hence strongly objected to the keeping of second vane near to the first one. Ouyang et al [18] not only supported the

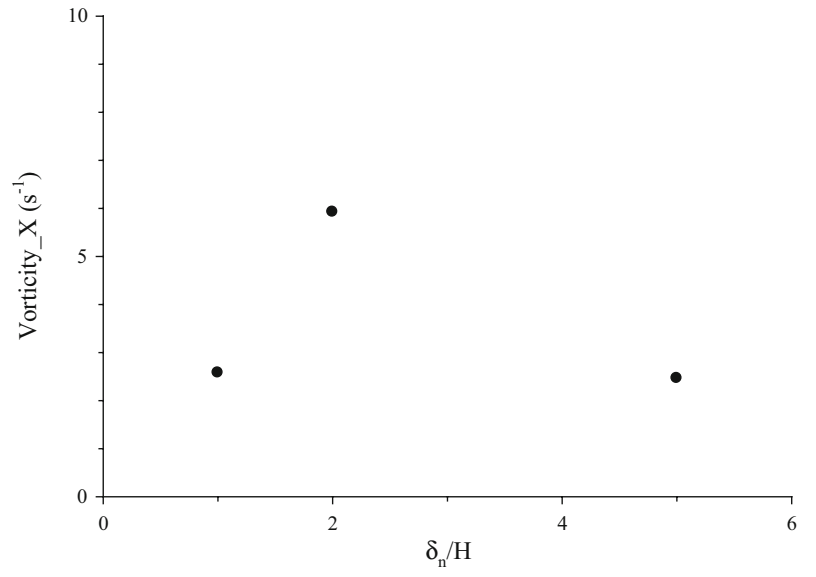

Figure 15. Variation of vorticity with transverse spacing between vanes.

observation of Odgaard and Wang [3] but also suggested that either use two vane row systems as vanes in between the two vanes generally not works effectively.

It can be seen from figure 15 that vorticity was seen to be maximum for $\delta_{\mathrm{n}}=2 \mathrm{H}$, which is in concurrence with the observations of Odgaard and Wang [3] and Wang and Odgaard [4]. Hence, it is suggested that by keeping vanes at a distance of two times the vane height, an optimum strength of circulation can be obtained.

7.1.3 Longitudinal spacing of vane array: In the literature, in multiple vane array arrangements, more emphasis was given to the lateral spacing of vanes, a few studies have been conducted to show the effect of longitudinal spacing. Odgaard and Wang [3] observed that by changing longitudinal spacing of vane arrays from $15 \mathrm{H}$ to $30 \mathrm{H}$, the induced bed level change from submerged vanes was reduced up to $20 \%$. Voisin and Townsend [7] proposed that by putting vanes at a distance of 0.7 times width, vanes will interact effectively. Allahyonesi et al [20] proposed that keeping vane arrays at a distance of $4 \mathrm{H}$, an effective diversion of sediment in the away direction from intake was obtained. Thus, it can be seen that there is no mutual agreement among the various investigators regarding the distance vane arrays should be placed so that an effective circulation can be obtained. In the present study we are proposing a method to optimize longitudinal vane spacing (figure 16).

A plot was constructed between non-dimensionalized vorticity (non-dimensionalized with the maximum vorticity just at the tip of vane) and normalized longitudinal distance (normalized with vane height). In this method an attempt was made to place vane rows in accordance with the percentage of vorticity required downstream. Now suppose we have to obtain the $50 \%$ of the original vorticity, so watch the $\%$ vorticity from vertical axis and from horizontal axis, read the corresponding value of $\mathrm{x} / \mathrm{H}$. Thus, considering the obtained " $\mathrm{x}$ " as the optimum value, the next array of 


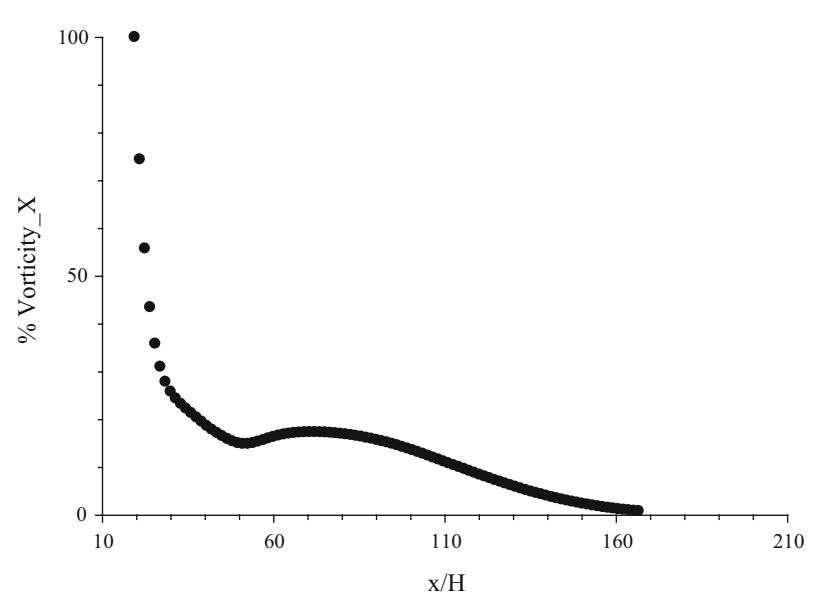

Figure 16. Variation of vorticity with longitudinal spacing between vanes.

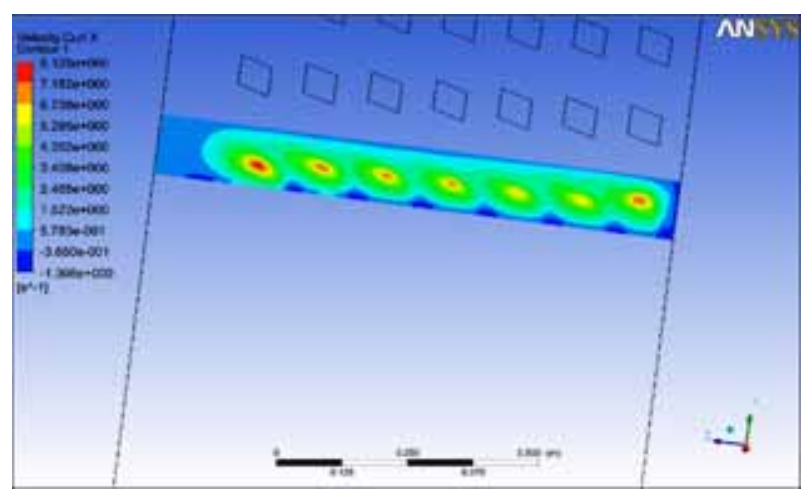

Figure 17. Variation of vorticity along the longitudinal distance for $\mathrm{x}=3 \mathrm{H}$.

submerged vane is placed and process is repeated until last array of vanes has been installed in the flow region. Thus, this method removes the ambiguity of placing vane array longitudinally in order to obtain optimum circulations and also gives the investigator freedom to place the submerged vane array in accordance with the strength of vorticity required downstream.

\section{Flow pattern around and downstream of vane arrays}

In case of multiple vane arrays system, it was observed that near the submerged vanes a large vortical field exists as can be seen in figure 17. A large field of turbulence was observed for observations at $\mathrm{x}=3 \mathrm{H}$. At further downstream, it was observed that vortices interacted with each other to make a large vortical field with a less effective vorticity (figures 18 and 19). It was further observed that going further downstream vorticity was reduced and effects of submerged vanes were reduced. Due to reduction in effective vorticity and simultaneous effect of viscosity on

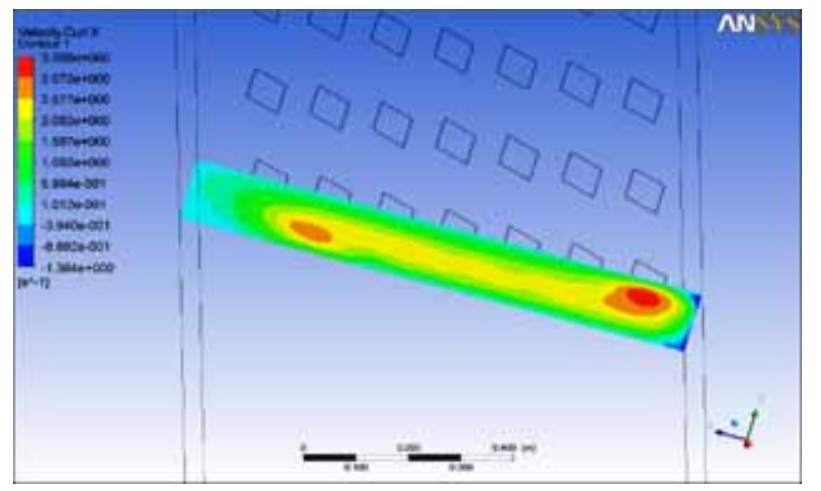

Figure 18. Variation of vorticity along the longitudinal distance for $\mathrm{x}=8 \mathrm{H}$.

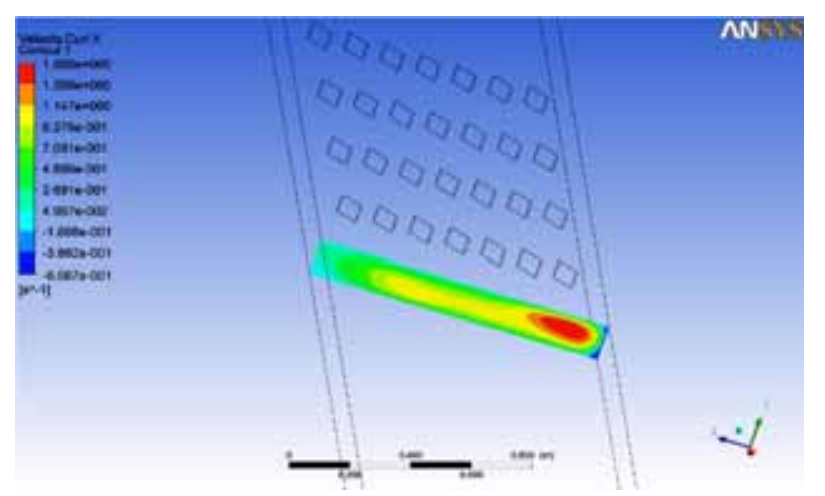

Figure 19. Variation of vorticity along the longitudinal distance for $\mathrm{x}=20 \mathrm{H}$.

the generated vortices, they were completely diminished in the flow.

\section{Conclusions}

In case of single vane arrangement, it was observed that by keeping submerged vane at an angle of $30^{\circ}$, maximum amount of secondary currents can be achieved. Further, height of vane $\mathrm{H}=0.4$ times the depth of flow produces maximum amount of secondary currents. It was observed that due to a larger contact area, a larger lift was obtained, thus vane length cannot be optimized. The leading edge assisted in generation of initial vortex by creating tip vortices from it. Also two counter-rotating vortices were observed in the downstream side of vane. The reason for their generation was the proximity of stagnation line to leading edge which has smaller pressure area than the trailing edge. The vortex generated from leading edge breaks down under suction pressure to form the pair. In case of multiple vane arrays, it was observed that in order to generate coherent vortical structure, vanes should be placed in an array at a transverse distance of two times the vane 
height. It was observed that many of the vane parameters were in accordance with the recommendations made by Odgaard and associates.

\section{References}

[1] Odgaard A J and Spoljaric A 1986 Sediment control by submerged vanes. J. Hydraulic Eng. ASCE 112(12): 1164-1181

[2] Odgaard A J and Mosconi C E 1987 Stream-bank protection by submerged vanes. J. Hydraulic Eng. ASCE 113(4): 520-536

[3] Odgaard A J and Wang Y 1991a Sediment management with submerged vanes. Theory: I. J. Hydraulic Eng. ASCE 117(3): 267-283

[4] Wang Y and Odgaard A J 1993 Flow control with vorticity. J. Hydraulic Res. IAHR 31(4): 549-562

[5] Odgaard A J and Kennedy J F 1983 River bend bank protection by submerged vanes. J. Hydraulic Eng. ASCE 109(8): $1161-1173$

[6] Han S S, Biron P M and Ramamurthy A S 2011 Three dimensional modeling of flow in sharp bends with vanes. $J$. Hydraulic Res. IAHR 49(1): 64-72

[7] Voisin A and Townsend R D 2002 Model testing of submerged vanes in strongly curved narrow channel bends. Canadian J. Civil Eng. NRC Research Press 29: 37-49

[8] Barkdoll B D, Ettema R and Odgaard A J 1999 Sediment control at lateral diversions: limits and enhancements to vane use. J. Hydraulic Eng. ASCE 125(8): 862-870

[9] Wang Y, Odgaard A J, Melville B W and Jain S C 1996 Sediment control at water intakes. J. Hydraulic Eng. ASCE, 122(6): 353-356
[10] Marelius F and Sinha S K 1998 Experimental analysis of flow past submerged vanes. J. Hydraulic Eng. ASCE 124(5): 542-545

[11] Johnson P A, Hey R D, Tessier M and Rosgen D L 2001 Use of vanes for control of scour hole for vertical wall abutments. J. Hydraulic Eng. ASCE 127(9): 772-778

[12] Tan S K, Guoliang Y, Lim S Y and Ong M C 2005 Flow structure and sediment motion around submerged vanes in open channel. J. Waterway, Port, Coastal Ocean Eng. ASCE 131(3): 132-136

[13] Bhuyian F, Hey R D and Wormleaton P R 2010 Bank attached vanes for bank erosion control and restoration of river meanders. J. Hydraulic Eng. ASCE 136(9): 583-596

[14] Gupta U P, Ojha C S P and Sharma N 2010 Enhancing utility of submerged vanes with collar. J. Hydraulic Eng. ASCE 136(9): 651-655

[15] Flokstra C 2006 Modelling of submerged vanes. J. Hydraulic Res. IAHR 44(5): 591-602

[16] Ouyang H T 2009 Investigation on the dimensions and shape of a submerged vane for sediment management in alluvial channels. J. Hydraulic Eng. ASCE 135(3): 209-217

[17] Bertin J J and Smith M L 1979 Aerodynamics for engineers, First edition, Prentice Hall, New Jersey, USA

[18] Ouyang H T, Lai J S, Yu H and Lu C H 2008 Interaction between submerged vanes for sediment management. $J$. Hydraulic Res. IAHR 46(5): 620-627

[19] Sinha S K and Marelius F 2000 Analysis of flow past submerged vanes. J. Hydraulic Res. IAHR 38(1): 65-71

[20] Allahyonesi H, Omid M H and Haghiabi A M 2008 A study of effects of longitudinal arrangement sediment behavior near intake structures. J. Hydraulic Res. IAHR 46(6): 814-819 